\title{
Value proposition of robotic thoracic surgery in high volume centers
}

\author{
Peter J. Kneuertz, Robert E. Merritt \\ Thoracic Surgery Division, Department of Surgery, The Ohio State University Wexner Medical Center, Columbus, OH, USA \\ Correspondence to: Peter J. Kneuertz. Thoracic Surgery Division, Department of Surgery, The Ohio State University Wexner Medical Center, \\ Columbus, OH, USA. Email: Peter.Kneuertz@osumc.edu.
}

Submitted Mar 11, 2019. Accepted for publication Apr 12, 2019.

doi: 10.21037/acs.2019.04.12

View this article at: http://dx.doi.org/10.21037/acs.2019.04.12

\section{Comment}

Several articles in the March 2019 issue of the Annals of Cardiothoracic Surgery on Robotic Thoracic Surgery address the financial cost, resource utilization and value of robotic thoracic surgery. The value of robotics, as it compares to the previously established minimally invasive approach of video-assisted thoracoscopic surgery (VATS), appears to be one important issue for the practicing general thoracic surgeon and the health system looking to adopt this technology in our field. For surgical procedures, value can be defined as the cost relative to outcomes and quality, as compared to alternative approaches/procedures.

Specific to pulmonary lobectomy, we provided a systematic review of the literature in this issue on cost as compared to VATS and the traditional open thoracotomy approach (1). In this review, we showed that robotic lobectomy was still more costly than VATS. We also noted that the cost of robotic lobectomy varied significantly between studies. Although some of the variability was likely due to different cost definitions, it became clear that most of the studies on cost to that date (prior to 2018) were derived from the early experience with robotic lobectomy. In a thoughtful discussion of the wider issues of resource implication of robotics, the guest editor Dr. Stamenkovic points to the close relationship between cost of the robotic technology (i.e., disposables, drapes and staplers), as well as other hospital resources that drive cost, such as operating room time and length of stay (2). Recently, we have critically reviewed our experience with robotic lobectomy to better understand the value of robotics at a high-volume center. We found that the cost of postoperative hospitalization was a major contributor, accounting for approximately $50 \%$ of total hospital cost. Hospital expenses with every additional day, associated with postoperative complications, was over
$10 \%$ of the total cost accrued per patient (3). Reduction of costly postoperative complications and shortening the length of stay, are therefore important opportunities for cost savings in order to improve cost-effectiveness.

We would like to point the reader to an updated value assessment and currently largest single-center comparison of cost between robotic, VATS and open lobectomy, which is not included in the previous review article. In this study, we demonstrated that there was no difference in cost between robotic and VATS lobectomy (4). This finding was associated with an average shorter operating room time as compared with VATS and fewer costs accrued in the postoperative period, associated with the surgical experience and process improvement efforts at a high-volume center. We further agree with the guest editor, that the cost per case derived from the currently large capital investment required for the purchase and maintenance of the robotic platform, is directly related to its utilization (2). These indirect costs may be reduced significantly when distributed amongst various surgeons and specialties at the individual hospital.

Therefore, we conclude that the newest evidence shows that robotic thoracic surgery may in fact be a value proposition for high-volume centers committed to this technology.

\section{Acknowledgments}

None.

\section{Footnote}

Conflicts of Interest: Dr. Merritt is a speaker for Intuitive Surgical. Dr. Kneuertz has no conflicts of interest to 
declare.

\section{References}

1. Singer E, Kneuertz PJ, D'Souza DM, et al. Understanding the financial cost of robotic lobectomy: calculating the value of innovation? Ann Cardiothorac Surg 2019;8:194-201.

2. Stamenkovic S, Slight RD. Resource implications of robotic thoracic surgery: what are the wider issues? Ann

Cite this article as: Kneuertz PJ, Merritt RE. Value proposition of robotic thoracic surgery in high volume centers. Ann Cardiothorac Surg 2019;8(3):E1-E2. doi: 10.21037/ acs.2019.04.12
Cardiothorac Surg 2019;8:250-4.

3. Kneuertz PJ, Singer E, D'Souza DM, et al. Postoperative complications decrease the cost-effectiveness of roboticassisted lobectomy. Surgery 2019;165:455-60.

4. Kneuertz PJ, Singer E, D'Souza DM, et al. Hospital cost and clinical effectiveness of robotic-assisted versus videoassisted thoracoscopic and open lobectomy: A propensity score-weighted comparison. J Thorac Cardiovasc Surg 2019. [Epub ahead of print]. 